\title{
Viscosity-Projection Method for a Family of General Equilibrium Problems and Asymptotically Strict Pseudocontractions in the Intermediate Sense
}

\author{
Dao-Jun Wen \\ College of Mathematics and Statistics, Chongqing Technology and Business University, Chongqing 400067, China \\ Correspondence should be addressed to Dao-Jun Wen; wendaojun@ctbu.edu.cn
}

Received 4 August 2013; Accepted 12 September 2013

Academic Editors: S. Amat, I. Beg, and S. A. Mohiuddine

Copyright (C) 2013 Dao-Jun Wen. This is an open access article distributed under the Creative Commons Attribution License, which permits unrestricted use, distribution, and reproduction in any medium, provided the original work is properly cited.

In this paper, a Meir-Keeler contraction is introduced to propose a viscosity-projection approximation method for finding a common element of the set of solutions of a family of general equilibrium problems and the set of fixed points of asymptotically strict pseudocontractions in the intermediate sense. Strong convergence of the viscosity iterative sequences is obtained under some suitable conditions. Results presented in this paper extend and unify the previously known results announced by many other authors.

\section{Introduction}

Let $H$ be a real Hilbert space with inner product $\langle\cdot, \cdot\rangle$ and norm $\|\cdot\|$, respectively. Let $C$ be a nonempty closed convex subset of $H$. Let $A: C \rightarrow H$ be a nonlinear mapping and $F$ : $C \times C \rightarrow \mathbb{R}$ be a bifunction, where $\mathbb{R}$ denotes the set of real numbers. We consider the following generalized equilibrium problem: Find $x \in C$ such that

$$
F(x, y)+\langle A x, y-x\rangle \geq 0, \quad \forall y \in C .
$$

We use $\operatorname{EP}(F, A)$ to denote the set of solution of problem (1). If $A \equiv 0$, the zero mapping, then the problem (1) reduces to the normal equilibrium problem: Find $x \in C$ such that

$$
F(x, y) \geq 0, \quad \forall y \in C .
$$

We use $\mathrm{EP}(F)$ to denote the set of solution of problem (2). If $F \equiv 0$, then the problem (1) reduces to the classical variational inequality problem: Find $x \in C$ such that

$$
\langle A x, y-x\rangle \geq 0, \quad \forall y \in C .
$$

We use $\mathrm{VI}(C, A)$ to denote the set of solution of problem (3). The generalized equilibrium problem (1) is very general in the sense that it includes, as special cases, saddle point problems, variational inequalities, optimization problems, mini-max problems, the Nash equilibrium problem in noncooperative games, and others (see, e.g., [1-4]).

Recall that a nonlinear mapping $T: C \rightarrow C$ is said to be nonexpansive if

$$
\|T x-T y\| \leq\|x-y\|, \quad \forall x, y \in C .
$$

$T$ is said to be uniformly $L$-Lipschitz continuous if there exists a constant $L>0$ such that

$$
\left\|T^{n} x-T^{n} y\right\| \leq L\|x-y\|, \quad n \geq 1, \forall x, y \in C .
$$

$T$ is said to be asymptotically nonexpansive if there exists a sequence $k_{n} \in[1, \infty)$ with $k_{n} \rightarrow 1$ as $n \rightarrow \infty$ such that

$$
\left\|T^{n} x-T^{n} y\right\| \leq k_{n}\|x-y\|, \quad n \geq 1, \forall x, y \in C .
$$

$T$ is said to be asymptotically nonexpansive in the intermediate sense [5] if it is continuous and the following inequality holds:

$$
\limsup _{n \rightarrow \infty} \sup _{x, y \in C}\left(\left\|T^{n} x-T^{n} y\right\|-\|x-y\|\right) \leq 0 .
$$

Putting $\xi_{n}=\max \left\{0, \sup _{x, y \in C}\left(\left\|T^{n} x-T^{n} y\right\|-\|x-y\|\right)\right\}$, we see that $\xi_{n} \rightarrow 0$ as $n \rightarrow \infty$. Then scheme (7) is reduced to the following:

$$
\left\|T^{n} x-T^{n} y\right\| \leq\|x-y\|+\xi_{n}, \quad \forall x, y \in C .
$$


The class of asymptotically nonexpansive mappings in the intermediate sense was introduced by Kirk [5] as a generalization of the class of asymptotically nonexpansive mappings. It is known that, if $C$ is a nonempty bounded closed convex subset of a real Hilbert space $H$, then every asymptotically nonexpansive self-mapping in the intermediate sense has a fixed point (see, e.g., [6]).

Recall also that $T$ is said to be a $\lambda$-strict pseudocontraction $[7,8]$ if there exists a coefficient $\lambda \in[0,1)$ such that

$$
\begin{array}{r}
\|T x-T y\|^{2} \leq\|x-y\|^{2}+\lambda\|(I-T) x-(I-T) y\|^{2}, \\
\forall x, y \in C .
\end{array}
$$

$T$ is said to be an asymptotically $\lambda$-strict pseudocontraction $[9,10]$ if there exists a sequence $k_{n} \in[1, \infty)$ with $k_{n} \rightarrow 1$ as $n \rightarrow \infty$ and a constant $\lambda \in[0,1)$ such that

$$
\begin{array}{r}
\left\|T^{n} x-T^{n} y\right\|^{2} \leq k_{n}\|x-y\|^{2}+\lambda\left\|\left(x-T^{n} x\right)-\left(y-T^{n} y\right)\right\|^{2}, \\
n \geq 1, \forall x, y \in C .
\end{array}
$$

$T$ is said to be an asymptotically $\lambda$-strict pseudocontraction in the intermediate sense $[11,12]$ if there exists a sequence $k_{n} \in$ $[1, \infty)$ with $k_{n} \rightarrow 1$ as $n \rightarrow \infty$ and a constant $\lambda \in[0,1)$ such that

$$
\begin{array}{r}
\limsup _{n \rightarrow \infty} \sup _{x, y \in C}\left(\left\|T^{n} x-T^{n} y\right\|^{2}-k_{n}\|x-y\|^{2}\right. \\
\left.-\lambda\left\|\left(x-T^{n} x\right)-\left(y-T^{n} y\right)\right\|^{2}\right) \leq 0, \\
\forall x, y \in C .
\end{array}
$$

Putting $e_{n}=\max \left\{0, \sup _{x, y \in C}\left(\left\|T^{n} x-T^{n} y\right\|^{2}-k_{n}\|x-y\|^{2}-\right.\right.$ $\left.\left.\lambda\left\|\left(x-T^{n} x\right)-\left(y-T^{n} y\right)\right\|^{2}\right)\right\}$, we see that $e_{n} \rightarrow 0$ as $n \rightarrow \infty$. Then scheme (11) is reduced to the following:

$$
\begin{array}{r}
\left\|T^{n} x-T^{n} y\right\|^{2} \\
\leq k_{n}\|x-y\|^{2}+\lambda\left\|\left(x-T^{n} x\right)-\left(y-T^{n} y\right)\right\|^{2}+e_{n}, \\
n \geq 1, \forall x, y \in C .
\end{array}
$$

We use $\operatorname{Fix}(T)$ to denote the set of fixed point of $T$, that is, $\operatorname{Fix}(T)=\{x \in C: T x=x\}$. The class of asymptotically strict pseudocontractions in the intermediate sense was introduced as a generalization of the asymptotically strict pseudocontractions and asymptotically nonexpansive in the intermediate sense. Clearly, a nonexpansive mapping is a 0strict pseudocontraction, and an asymptotically nonexpansive mapping is an asymptotically 0 -strict pseudocontraction. (see, e.g., [7-12]).

Fixed point technique represent an important tool for finding the approximate solution of equilibrium problem and its variant forms, which have been studied extensively in recent years due to their applications in physics, economics, optimization, and pure and applied sciences. Some numerical methods have been proposed for finding a common element of the set of fixed point of various types of nonexpansive mappings and the set of solution of equilibrium problems with bifunctions satisfying certain conditions; see [8-20] and references therein.

In 2009, Qin et al. [10] introduced the following explicit iterative algorithm for finding a common fixed point of a finite family of asymptotically $\lambda_{i}$-strictly pseudocontractions $T_{i}$ for each $i=1,2, \ldots, N$

$$
x_{n}=\alpha_{n-1} x_{n-1}+\left(1-\alpha_{n-1}\right) T_{i(n)}^{h(n)} x_{n-1}, \quad n \geq 1,
$$

where $x_{0} \in C,\left\{\alpha_{n}\right\}_{n=0}^{\infty}$ is a sequence in $(0,1)$ and $n=[h(n)-$ $1] N+i(n), i=i(n)=1,2, \ldots, N$. They also obtain weak and strong convergence theorems based on the cyclic scheme above.

Recently, Sahu et al. [11] considered a new iterative scheme for asymptotically strictly pseudocontractive mappings in the intermediate sense. To be more precise, they proved the following theorem.

Theorem SXY. Let $C$ be a nonempty closed and convex subset of a real Hilbert space $H$ and $T: C \rightarrow C$ be a uniformly continuous asymptotically $\lambda$-strictly pseudocontractive mapping in the intermediate sense with a sequence $\left\{k_{n}\right\}$ such that $\operatorname{Fix}(T)$ is nonempty and bounded. Let $\left\{\alpha_{n}\right\}$ be a sequence in $[0,1]$ such that $0<\delta \leq \alpha_{n} \leq 1-\lambda$ for all $n \in \mathbb{N}$. Let $\left\{x_{n}\right\} \subset C$ be a sequence generated by the following (CQ) algorithm:

$$
\begin{gathered}
u=x_{1} \in C, \\
y_{n}=\left(1-\alpha_{n}\right) u_{n}+\alpha_{n} T^{n} x_{n}, \\
C_{n}=\left\{w \in C:\left\|y_{n}-w\right\|^{2} \leq\left\|x_{n}-w\right\|^{2}+\theta_{n}\right\}, \\
Q_{n}=\left\{w \in C:\left\langle x_{n}-w, u-x_{n}\right\rangle \geq 0\right\}, \\
x_{n+1}=P_{C_{n} \cap Q_{n}}(u),
\end{gathered}
$$

where $\theta_{n}=\left(k_{n}-1\right) \rho_{n}^{2}+e_{n}$ and $\rho_{n}=\sup \left\{\left\|x_{n}-p\right\|: p \epsilon\right.$ $\operatorname{Fix}(T)\}<\infty$. Then, $\left\{x_{n}\right\}$ converges strongly to $P_{\mathrm{Fix}(T)}(u)$, where $P_{\mathrm{Fix}(T)}$ is metric projection from $\mathrm{H}$ onto $\operatorname{Fix}(T)$.

In 2011, Hu and Cai [12] modified schemes (13) and (14) to the case of asymptotically strictly pseudocontractive mappings in the intermediate sense concerning the equilibrium problem and proposed the following modified hybrid method:

$$
\begin{gathered}
x_{0} \in C, \quad u_{0} \in C, \\
F\left(u_{n}, y\right)+\left\langle A x_{n}, y-u_{n}\right\rangle \\
+\frac{1}{r_{n}}\left\langle y-u_{n}, u_{n}-x_{n}\right\rangle \geq 0, \quad \forall y \in C, \\
z_{n}=\left(1-\beta_{n}\right) u_{n}+\beta_{n} T_{i(n)}^{h(n)} u_{n}, \\
y_{n}=\left(1-\alpha_{n}\right) u_{n}+\alpha_{n} z_{n},
\end{gathered}
$$




$$
\begin{gathered}
C_{n}=\left\{w \in C:\left\|y_{n}-w\right\|^{2} \leq\left\|x_{n}-w\right\|^{2}+\theta_{n}\right\}, \\
Q_{n}=\left\{w \in C:\left\langle x_{n}-w, x_{0}-x_{n}\right\rangle \geq 0\right\}, \\
x_{n+1}=P_{C_{n} \cap Q_{n}}\left(x_{0}\right),
\end{gathered}
$$

where $\theta_{n}=\left(k_{h(n)}-1\right) \rho_{n}^{2}+e_{h(n)} \rightarrow 0$ as $n \rightarrow \infty$ and $\rho_{n}=\sup \{\|$ $\left.x_{n}-p \|: p \in \Omega\right\}<\infty$. Moreover, they obtained convergence theorems under some suitable conditions.

On the other hand, Moudafi [13] introduced the following viscosity approximation method for fixed point problem of nonexpansive mapping

$$
x_{n+1}=\alpha_{n} f\left(x_{n}\right)+\left(1-\alpha_{n}\right) T x_{n}
$$

where $f$ is a contractive mapping. He proved that the viscosity iterative sequence $\left\{x_{n}\right\}$ convergence strongly to a fixed point of $T$, which is the unique solution of the variational inequality:

$$
\langle(I-f) x, z-x\rangle \geq 0, \quad \forall z \in \operatorname{Fix}(T) .
$$

Furthermore, S. Takahashi and W. Takahashi [14] and Inchan [15] modified the viscosity approximation methods for finding a common element of the set of fixed point problems and equilibrium problems.

In 2012, Kimura and Nakajo [16] introduced a Meir-Keeler contraction and proposed a modified viscosity approximations by the shrinking projection method in Hilbert spaces, the socalled viscosity-projection method. To be more precise, they proved the following theorem.

Theorem KN. Let $C$ be a nonempty closed convex subset of $H$, and let $\left\{T_{n}\right\}$ be a sequence of mappings of $C$ into itself with $\Omega=\bigcap_{n=1}^{\infty} \operatorname{Fix}\left(T_{n}\right) \neq \varnothing$ which satisfies the following condition: there exists $\left\{a_{n}\right\} \subset \mathbb{R}$ with $\liminf _{n \rightarrow \infty} a_{n}>-1$ such that $\|$ $T_{n} x-z\left\|^{2} \leq\right\| x-z\left\|^{2}-a_{n}\right\| x-T_{n} x \|^{2}$ for every $n \in \mathbb{N}, x \in C$, and $z \in \Omega$. Let $f$ be a Meir-Keeler contraction of $C$ into itself, and let $\left\{x_{n}\right\}$ be a sequence generated by

$$
\begin{gathered}
x_{1}=x \in C, \quad C_{1}=C \\
y_{n}=T_{n} x_{n}, \\
C_{n+1}=\left\{w \in C_{n}:\left\|y_{n}-w\right\|^{2} \leq\left\|x_{n}-w\right\|^{2}-a_{n}\left\|x_{n}-y_{n}\right\|^{2}\right\}, \\
x_{n+1}=P_{C_{n+1}} f\left(x_{n}\right),
\end{gathered}
$$

for each $n \in \mathbb{N}$. For every sequence $\left\{z_{n}\right\} \subset C$ and $z_{n} \rightarrow z \in C$ and $T_{n} z_{n} \rightarrow z$ imply that $z \in \Omega$. Then, $\left\{x_{n}\right\}$ converges strongly to $q \in \Omega$, which satisfies $q=P_{\Omega} f(q)$.

In this paper, inspired and motivated by research going on in this area, we introduce a new viscosity-projection method for a family of general equilibrium problems and asymptotically strict pseudocontractions in the intermediate sense, which is defined in the following way:

$$
\begin{gathered}
x_{1} \in C, \quad C_{1}=C, \\
u_{n}=F_{r_{M, n}}^{A_{M}} F_{r_{M-1, n}}^{A_{M-1}} \cdots F_{r_{2, n}}^{A_{2}} F_{r_{1, n}}^{A_{1}} x_{n}, \\
z_{n}=\left(1-\beta_{n}\right) u_{n}+\beta_{n} T_{i(n)}^{h(n)} u_{n}, \\
y_{n}=\left(1-\alpha_{n}\right) u_{n}+\alpha_{n} z_{n}, \\
C_{n+1}=\left\{w \in C_{n}:\left\|y_{n}-w\right\|^{2} \leq\left\|x_{n}-w\right\|^{2}+\theta_{n}\right\}, \\
x_{n+1}=P_{C_{n+1}} f\left(x_{n}\right),
\end{gathered}
$$

where $\theta_{n}=\left(k_{h(n)}-1\right) \rho_{n}^{2}+e_{h(n)} \rightarrow 0$ as $n \rightarrow \infty$ and $\rho_{n}=$ $\sup \left\{\left\|x_{n}-p\right\|: p \in \Omega\right\}<\infty$.

Our purpose is not only to extend the viscosity-projection method with a Meir-Keeler contraction to the case of a family of general equilibrium problems and asymptotically strict pseudocontractions in the intermediate sense, but also to obtain a strong convergence theorem by using the proposed schemes under some appropriate conditions. Results presented in this paper extend and unify the corresponding ones of $[10-13,16]$.

\section{Preliminaries}

Let $C$ be a nonempty closed convex subset of a real Hilbert space $H$ with inner product $\langle\cdot, \cdot\rangle$ and norm $\|\cdot\|$, respectively. We use notation $\rightarrow$ for weak convergence and $\rightarrow$ for strong convergence of a sequence. For every point $x \in H$, there exists a unique nearest point in $C$, denoted by $P_{C} x$, such that

$$
\left\|x-P_{C} x\right\| \leq\|x-y\|, \quad \forall y \in C .
$$

$P_{C}$ is called the metric projection of $H$ onto $C$ defined by $P_{C}(x)=\arg \min _{y \in C}\|x-y\|$. It is well known that $P_{C}$ is nonexpansive mapping, and $u=P_{C} x$ is equivalent to (see, e.g., [21]) the following:

$$
\langle x-u, u-y\rangle \geq 0, \quad \forall y \in C .
$$
if

Recall that a mapping $A: C \rightarrow H$ is said to be monotone

$$
\langle A x-A y, x-y\rangle \geq 0, \quad \forall x, y \in C .
$$

$A$ is said to be $r$-strongly monotone if there exists a constant $r>0$ such that

$$
\langle A x-A y, x-y\rangle \geq r\|x-y\|^{2}, \quad \forall x, y \in C .
$$

$A$ is said to be $\alpha$-inverse strongly monotone if there exists a constant $\alpha>0$ such that

$$
\langle A x-A y, x-y\rangle \geq \alpha\|A x-A y\|^{2}, \quad \forall x, y \in C .
$$

It is easy to see that if $A$ is an $\alpha$-inverse strongly monotone mapping from $C$ into $H$, then $A$ is $1 / \alpha$-Lipschitz continuous. 
To study the generalized equilibrium problem (1), we may assume that the bifunction $F: C \times C \rightarrow \mathbb{R}$ satisfies the following conditions:

(A1) $F(x, x)=0$ for all $x \in C$;

(A2) $F$ is monotone, that is, $F(x, y)+F(y, x) \leq 0$ for all $x, y \in C$;

(A3) for each $x, y, z \in C, \lim _{t \rightarrow 0} F(t z+(1-t) x, y) \leq$ $F(x, y)$;

(A4) for each $x \in C, y \mapsto F(x, y)$ is convex and lower semicontinuous.

Lemma 1 (see $[1,3]$ ). Let $F: C \times C \rightarrow \mathbb{R}$ be a bifunction satisfying (A1)-(A4). Then, for any $r>0$ and $x \in H$, there exists $z \in C$ such that

$$
F(z, y)+\frac{1}{r}\langle y-z, z-x\rangle \geq 0, \quad \forall y \in C .
$$

Further, if $F_{r} x=\{z \in C: F(z, y)+(1 / r)\langle y-z, z-x\rangle \geq$ $0, \forall y \in C\}$, then the following hold:

(1) $F_{r}$ is single-valued;

(2) $F_{r}$ is firmly nonexpansive, that is, $\left\|F_{r} x-F_{r} y\right\|^{2} \leq\left\langle F_{r} x-\right.$ $\left.F_{r} y, x-y\right\rangle$ for all $x, y \in H$;

(3) $\operatorname{Fix}\left(F_{r}\right)=E P(F)$;

(4) $E P(F)$ is closed and convex.

Lemma 2 (see [8]). In a Hilbert space $H$, there hold the following identities:

(i) $\|x+y\|^{2} \leq\|x\|^{2}+2\langle y,(x+y)\rangle$, for all $x, y \in H$;

(ii) $\|t x+(1-t) y\|^{2}=t\|x\|^{2}+(1-t)\|y\|^{2}-t(1-t)\|x-y\|^{2}$, for all $t \in[0,1]$, for all $x, y \in H$.

Lemma 3 (see [8]). Let $C$ be a nonempty closed convex subset of a real Hilbert space $H$. For any $x, y, z \in H$ and given also $a$ real number $a \in \mathbb{R}$, the set

$$
\left\{v \in C:\|y-v\|^{2} \leq\|x-v\|^{2}+\langle z, v\rangle+a\right\}
$$

is closed and convex.

Lemma 4 (see [11]). Let $C$ be a nonempty closed convex subset of a real Hilbert space $H$ and $T: C \rightarrow C$ be a uniformly L-Lipschitz continuous and asymptotically $\lambda$-strict pseudocontraction in the intermediate sense. Then $\operatorname{Fix}(T)$ is closed and convex.

Lemma 5 (see [11]). Let $C$ be a nonempty closed convex subset of a real Hilbert space $H$ and $T: C \rightarrow C$ be a uniformly L-Lipschitz continuous and asymptotically $\lambda$-strict pseudocontraction in the intermediate sense. Then $I-T$ is demiclosed at zero, that is, if the sequence $\left\{x_{n}\right\} \subset C$ such that $x_{n} \rightarrow x$ and $x_{n}-T x_{n} \rightarrow 0$ as $n \rightarrow \infty$, then $x \in \operatorname{Fix}(T)$.

Lemma 6 (see [11]). Let $C$ be a nonempty closed convex subset of a real Hilbert space $H$ and $T: C \rightarrow C$ be an asymptotically $\lambda$-strict pseudocontraction in the intermediate sense with $\gamma_{n}=$ $k_{n}-1$. Then

$$
\begin{aligned}
& \left\|T^{n} x-T^{n} y\right\| \\
& \leq \frac{1}{1-\lambda}\{\lambda\|x-y\| \\
& \left.\quad+\sqrt{\left[1+(1-\lambda) \gamma_{n}\right]\|x-y\|^{2}+(1-\lambda) e_{n}}\right\}, \\
& n \geq 1, \forall x, y \in C .
\end{aligned}
$$

Recall also that a mapping $f$ of a complete metric space $(X, d)$ into itself is called a contraction with coefficient $r \in(0,1)$ if $\|f(x)-f(y)\| \leq r\|x-y\|$, for all $x, y \in X$. It is known that $f$ has a unique fixed point (see, e.g., [22]). On the other hand, Meir and Keeler [23] defined the following mapping, called the Meir-Keeler contraction. A mapping $f: X \rightarrow X$ is called a Meir-Keeler contraction if, for every $\epsilon>0$, there exists $\delta>0$ such that $d(x, y)<\epsilon+\delta$ implies that

$$
d(f(x), f(y))<\epsilon, \quad \forall x, y \in X .
$$

We know that Meir-Keeler contraction is a generalization of contraction, and the following result, which extends the Banach contraction principle, is proved in [23].

Lemma 7 (see [23]). A Meir-Keeler contraction defined on a complete metric space has a unique fixed point.

Lemma 8 (see [24]). Let $f$ be a Meir-Keeler contraction on a convex subset $C$ of a Banach space $E$. Then, for every $\epsilon>0$, there exists $r \in(0,1)$ such that $\|x-y\| \geq \epsilon$ implies that

$$
\|f(x)-f(y)\| \leq r\|x-y\|, \quad \forall x, y \in C .
$$

Let $\left\{C_{n}\right\}$ be a sequence of nonempty closed convex subsets of $H$. We define a subset $s-L i_{n} C_{n}$ of $H$ as follows: $x \in s-L i_{n} C_{n}$ if and only if there exists $\left\{x_{n}\right\} \subset H$ such that $x_{n} \rightarrow x$ and $x_{n} \in C_{n}$ for all $n \in \mathbb{N}$. Similarly, a subset $w-L s_{n} C_{n}$ of $H$ is defined by $y \in w-L s_{n} C_{n}$ if and only if there exists a subsequence $\left\{C_{n_{i}}\right\}$ of $\left\{C_{n}\right\}$ and a sequence $\left\{y_{i}\right\} \subset H$ such that $y_{i} \rightarrow y$ and $y_{i} \in C_{n_{i}}$ for all $i \in \mathbb{N}$. If $C_{0} \subset H$ satisfies

$$
C_{0}=s-L i_{n} C_{n}=w-L s_{n} C_{n}
$$

it is said that $\left\{C_{n}\right\}$ converges to $C_{0}$ in the sense of Mosco [25], and we write $C_{0}=M-\lim _{n} C_{n}$. One of the simplest examples of Mosco convergence is a decreasing sequence $\left\{C_{n}\right\}$ with respect to inclusion. The Mosco limit of such a sequence is $\bigcap_{n=1}^{\infty} C_{n}$. For more details, see [26].

Lemma 9 (see [27]). Let $\left\{C_{n}\right\}$ be a sequence of nonempty closed convex subsets of $H$. If $C_{0}=M-\lim _{n} C_{n}$ exists and is nonempty, then, for each $x \in H,\left\{P_{C_{n}} x\right\}$ converges strongly to $P_{\mathrm{C}_{0}} x$.

For the rest of this paper, let $F_{m}: C \times C \rightarrow \mathbb{R}$ be $a$ bifunction satisfying (A1)-(A4) and $A_{m}: C \rightarrow H$ be an $\alpha_{m^{-}}$ inverse strongly monotone mapping, for some $m=1,2, \ldots, M$. 
For each $r_{m}>0$ and $x \in H$, define a mapping $F_{r_{m}}^{A_{m}}: H \rightarrow C$ as follows:

$$
\begin{aligned}
F_{r_{m}}^{A_{m}}(x)=\left\{z \in C: F_{m}(z, y)+\left\langle A_{m} x, y-z\right\rangle\right. \\
\left.+\frac{1}{r_{m}}\langle y-z, z-x\rangle \geq 0, \forall y \in C\right\} .
\end{aligned}
$$

It follows from Lemma 1 that $F_{r_{m}}^{A_{m}}=F_{r_{m}}\left(I-r_{m} A_{m}\right)$ for each $m=1,2, \ldots, M$.

Let $T_{i}: C \rightarrow C$ be a uniformly $L_{i}$-Lipschitz continuous and asymptotically $\lambda_{i}$-strict pseudocontractive mapping in the intermediate sense with the sequences $\left\{k_{n, i}\right\} \subset[1, \infty)$ such that $\lim _{n \rightarrow \infty} k_{n, i}=1$ and $\left\{e_{n, i}\right\} \subset[0, \infty)$ such that $\lim _{n \rightarrow \infty} e_{n, i}=0$, for some $i=1,2, \ldots, N$, that is,

$$
\begin{array}{r}
\left\|T_{i}^{n} x-T_{i}^{n} y\right\|^{2} \leq k_{n, i}\|x-y\|^{2} \\
+\lambda_{i}\left\|\left(x-T_{i}^{n} x\right)-\left(y-T_{i}^{n} y\right)\right\|^{2}+e_{n, i} \\
\forall x, y \in C .
\end{array}
$$

Remark that $L=\max \left\{L_{i}: 1 \leq i \leq N\right\}, \lambda=\max \left\{\lambda_{i}: 1 \leq i \leq\right.$ $N\}, k_{n}=\max \left\{k_{n, i}: 1 \leq i \leq N, n \in \mathbb{N}\right\}$ and $e_{n}=\max \left\{e_{n, i}: 1 \leq\right.$ $i \leq N, n \in \mathbb{N}\}$.

\section{Main Results}

Theorem 10. Let $C$ be a nonempty closed convex subset of Hilbert space $H$. Let $F_{m}: C \times C \rightarrow \mathbb{R}$ be a bifunction satisfying (A1)-(A4), and let $A_{m}: C \rightarrow H$ be an $\alpha_{m^{-}}$ inverse strongly monotone mapping, for each $m=1,2, \ldots, M$. Let $T_{i}: C \rightarrow C$ be a uniformly $L_{i}$-Lipschitz continuous and asymptotically $\lambda_{i}$-strict pseudocontractive mapping in the intermediate sense with the sequences $\left\{k_{n, i}\right\}$ and $\left\{e_{n, i}\right\}$ for each $i=1,2, \ldots, N$. If $f$ is a Meir-Keeler contraction of $C$ into itself and $\Omega=\left(\bigcap_{i=1}^{N} \operatorname{Fix}\left(T_{i}\right)\right) \cap\left(\bigcap_{m=1}^{M} E P\left(F_{m}, A_{m}\right)\right)$ is nonempty and bounded. Assume that $\left\{\alpha_{n}\right\},\left\{\beta_{n}\right\}$ are sequences in $[0,1]$ such that $0<a \leq \alpha_{n} \leq 1,0<b \leq \beta_{n} \leq 1-\lambda$ and $\left\{r_{m, n}\right\} \subset(0, \infty)$ such that $r_{m, n} \in[c, d] \subset\left(0,2 \alpha_{m}\right)$, for each $m=1,2, \ldots, M$ and $n \in \mathbb{N}$. Then the sequence $\left\{x_{n}\right\}$ generated by (19) converges strongly to $q=P_{\Omega} f(q)$.

Proof. We split the proof into six steps.

Step 1. We prove that $P_{\Omega} f$ exists a unique fixed point. To do this, we first show that $\left(I-r_{m, n} A_{m}\right)$ is nonexpansive for each $m=1,2, \ldots, M$. Indeed,

$$
\begin{aligned}
&\left\|\left(I-r_{m, n} A_{m}\right) x-\left(I-r_{m, n} A_{m}\right) y\right\|^{2} \\
&=\left\|(x-y)-r_{m, n}\left(A_{m} x-A_{m} y\right)\right\|^{2} \\
&=\|x-y\|^{2}-2 r_{m, n}\left\langle A_{m} x-A_{m} y, x-y\right\rangle \\
&+r_{m, n}^{2}\left\|A_{m} x-A_{m} y\right\|^{2} \\
& \leq\|x-y\|^{2}-r_{m, n}\left(2 \alpha_{m}-r_{m, n}\right)\left\|A_{m} x-A_{m} y\right\|^{2} \\
& \leq\|x-y\|^{2} .
\end{aligned}
$$

It follows that $\left(I-r_{m, n} A_{m}\right)$ is nonexpansive. By Lemma 1 , we know that $\bigcap_{m=1}^{M} \operatorname{EP}\left(F_{m}, A_{m}\right)$ is closed and convex. We also know from Lemma 4 that $\bigcap_{i=1}^{N} \operatorname{Fix}\left(T_{i}\right)$ is closed, and convex. Hence, $\Omega=\left(\bigcap_{i=1}^{N} \operatorname{Fix}\left(T_{i}\right)\right) \cap\left(\bigcap_{m=1}^{M} \operatorname{EP}\left(F_{m}, A_{m}\right)\right)$ is a nonempty, closed and convex subset of $C$. Consequently, $P_{\Omega}$ is well-defined. Since $P_{\Omega}$ is nonexpansive, the composed mapping $P_{\Omega} f$ of $C$ into itself is a Meir-Keeler contraction on $C$; see [24, Proposition 3]. By Lemma 7, there exists a unique fixed point $z \in \Omega$ of $P_{\Omega} f$.

Step 2. We show that $C_{n}$ is closed convex subset of $C$ for each $n \geq 1$. By the assumption of $C_{n+1}$, it is easy to see that $C_{n}$ is closed for each $n \geq 1$. We only show that $C_{n}$ is convex for each $n \geq 1$. It is obvious that $C_{1}=C$ is closed and convex. Suppose that $C_{k}$ is closed and convex for some $k \geq 1$. For any $w \in C_{k}$, we see that

$$
\left\|y_{k}-w\right\|^{2} \leq\left\|x_{k}-w\right\|^{2}+\theta_{k}, \quad k \geq 1,
$$

is equivalent to

$$
2\left\langle x_{k}-y_{k}, w\right\rangle \leq\left\|x_{k}\right\|^{2}-\left\|y_{k}\right\|^{2}+\theta_{k} \text {. }
$$

Taking $w_{1}$ and $w_{2}$ in $C_{k+1}$ and putting $\bar{w}=t w_{1}+(1-t) w_{2}$, it follows that $w_{1}, w_{2} \in C_{k}$, and so

$$
\begin{aligned}
& 2\left\langle x_{k}-y_{k}, w_{1}\right\rangle \leq\left\|x_{k}\right\|^{2}-\left\|y_{k}\right\|^{2}+\theta_{k}, \\
& 2\left\langle x_{k}-y_{k}, w_{2}\right\rangle \leq\left\|x_{k}\right\|^{2}-\left\|y_{k}\right\|^{2}+\theta_{k} .
\end{aligned}
$$

Combing (36) and (37), we obtain that

$$
2\left\langle x_{k}-y_{k}, \bar{w}\right\rangle \leq\left\|x_{k}\right\|^{2}-\left\|y_{k}\right\|^{2}+\theta_{k}
$$

That is,

$$
\left\|y_{k}-\bar{w}\right\|^{2} \leq\left\|x_{k}-\bar{w}\right\|^{2}+\theta_{k}
$$

In view of the convexity of $C_{k}$, we see that $\bar{w} \in C_{k}$. This implies that $\bar{w} \in C_{k+1}$. Therefore, $C_{k+1}$ is convex. Consequently, $C_{n}$ is closed and convex for each $n \geq 1$.

Step 3. We show that $\Omega \subset C_{n}$ for each $n \geq 1$. Put $\Theta_{n}^{m}=F_{r_{m, n}}^{A_{m}}$ $F_{r_{m-1, n}}^{A_{m-1}} \cdots F_{r_{2, n}}^{A_{2}} F_{r_{1, n}}^{A_{1}}$ for every $m=1,2, \ldots, M$ and $\Theta_{n}^{0}=I$ for all $n \in \mathbb{N}$. Note that $F_{r_{m, n}}^{A_{m}}=F_{r_{m, n}}\left(I-r_{m, n} A_{m}\right)$ is nonexpansive. Therefore, $u_{n}=\Theta_{n}^{M} x_{n}$. It is obvious that $\Omega \subset C_{1}=C$. 
Suppose that $\Omega \subset C_{k}$ for some $k \geq 1$. Taking $p \in \Omega$, it follows from Lemma 1 that

$$
\begin{aligned}
\left\|u_{n}-p\right\| & =\left\|\Theta_{n}^{M} x_{n}-\Theta_{n}^{M} p\right\| \\
= & \| F_{r_{M, n}}\left(I-r_{M, n} A_{M}\right) \Theta_{n}^{M-1} x_{n} \\
& \quad-F_{r_{M, n}}\left(I-r_{M, n} A_{M}\right) \Theta_{n}^{M-1} p \| \\
\leq & \|\left(I-r_{M, n} A_{M}\right) \Theta_{n}^{M-1} x_{n} \\
& \quad-\left(I-r_{M, n} A_{M}\right) \Theta_{n}^{M-1} p \| \\
\leq & \left\|\Theta_{n}^{M-1} x_{n}-\Theta_{n}^{M-1} p\right\| \\
\vdots & \\
\leq & \left\|\Theta_{n}^{0} x_{n}-\Theta_{n}^{0} p\right\| \\
& =\left\|x_{n}-p\right\| .
\end{aligned}
$$

From (19), we observe that

$$
\begin{aligned}
\left\|z_{n}-p\right\|^{2}= & \left\|\left(1-\beta_{n}\right) u_{n}+\beta_{n} T_{i(n)}^{h(n)} u_{n}-p\right\|^{2} \\
= & \left(1-\beta_{n}\right)\left\|u_{n}-p\right\|^{2}+\beta_{n}\left\|T_{i(n)}^{h(n)} u_{n}-p\right\|^{2} \\
& -\beta_{n}\left(1-\beta_{n}\right)\left\|u_{n}-T_{i(n)}^{h(n)} u_{n}\right\|^{2} \\
\leq & \left(1-\beta_{n}\right)\left\|u_{n}-p\right\|^{2} \\
& +\beta_{n}\left[k_{h(n)}\left\|u_{n}-p\right\|^{2}+\lambda\left\|u_{n}-T_{i(n)}^{h(n)} u_{n}\right\|^{2}+e_{h(n)}\right] \\
& -\beta_{n}\left(1-\beta_{n}\right)\left\|u_{n}-T_{i(n)}^{h(n)} u_{n}\right\|^{2} \\
\leq & k_{h(n)}\left\|u_{n}-p\right\|^{2}-\beta_{n}\left(1-\beta_{n}-\lambda\right) \\
& \times\left\|u_{n}-T_{i(n)}^{h(n)} u_{n}\right\|^{2}+\beta_{n} e_{h(n)} \\
\leq & k_{h(n)}\left\|u_{n}-p\right\|^{2}+\beta_{n} e_{h(n)} .
\end{aligned}
$$

By virtue of convexity of $\|\cdot\|^{2}$, combining (40) and (41), we have

$$
\begin{aligned}
\left\|y_{n}-p\right\|^{2}= & \left\|\left(1-\alpha_{n}\right) u_{n}+\alpha_{n} z_{n}-p\right\|^{2} \\
\leq & \left(1-\alpha_{n}\right)\left\|u_{n}-p\right\|^{2}+\alpha_{n}\left\|z_{n}-p\right\|^{2} \\
\leq & \left(1-\alpha_{n}\right)\left\|u_{n}-p\right\|^{2} \\
& +\alpha_{n}\left[k_{h(n)}\left\|u_{n}-p\right\|^{2}+\beta_{n} e_{h(n)}\right] \\
\leq & \left\|u_{n}-p\right\|^{2}+\left(k_{h(n)}-1\right)\left\|u_{n}-p\right\|^{2}+e_{h(n)} \\
= & \left\|u_{n}-p\right\|^{2}+\theta_{n} \\
\leq & \left\|x_{n}-p\right\|^{2}+\theta_{n},
\end{aligned}
$$

where $\theta_{n}=\left(k_{h(n)}-1\right) \rho_{n}^{2}+e_{h(n)} \rightarrow 0$ as $n \rightarrow \infty$ and $\rho_{n}=$ $\sup \left\{\left\|x_{n}-p\right\|: p \in \Omega\right\}<\infty$. Setting $n=k$ in (40)-(43), it follows that $p \in C_{k+1}$. Therefore, $\Omega \in C_{n}$ for each $n \geq 1$.

Step 4. Next, we prove that $\lim _{n \rightarrow \infty} x_{n}=q$, where $q=$ $P_{\bigcap_{n=1}^{\infty} C_{n}} f(q)$. Note that $C_{n}$ is a closed convex subset of $H$ and $\emptyset \neq \Omega \subset C_{n+1} \subset C_{n}$ for all $n \in \mathbb{N}$. Thus, $\left\{x_{n}\right\}$ is welldefined. Since the composed mapping $P_{\bigcap_{n=1}^{\infty} C_{n}} f$ is a MeirKeeler contraction on $C$, there exists a unique fixed point $q=P_{\bigcap_{n=1}^{\infty} C_{n}} f(q) \in \bigcap_{n=1}^{\infty} C_{n}$ by Lemma 7. Let $w_{n}=P_{C_{n}} f(q)$ for each $n \in \mathbb{N}$. We get $\bigcap_{n=1}^{\infty} C_{n}=M-\lim _{n} C_{n}$, since $\Omega \subset$ $C_{n+1} \subset C_{n}$ for every $n \in \mathbb{N}$. Thus, from Lemma 9 , we get

$$
w_{n} \longrightarrow P_{\bigcap_{n=1}^{\infty} C_{n}} f(q)=q .
$$

We prove that $x_{n} \rightarrow q$ in the following. If it were so, it would hold that $\limsup _{n \rightarrow \infty}\left\|x_{n}-q\right\|>0$. Let $\epsilon>0$, such that $\lim \sup _{n \rightarrow \infty}\left\|x_{n}-q\right\|>\epsilon$. By the definition of MeirKeeler contraction, there exists $\delta>0$ with $\limsup _{n \rightarrow \infty} \|$ $x_{n}-q \|>\epsilon+\delta$ such that $\|x-y\|<\epsilon+\delta$ implies that

$$
\|f(x)-f(y)\|<\epsilon, \quad \forall x, y \in C .
$$

From Lemma 8, there exists $r \in(0,1)$ such that $\|x-y\| \geq \epsilon+\delta$ implies that

$$
\|f(x)-f(y)\|<r\|x-y\|, \quad \forall x, y \in C .
$$

By (44), there exists $n_{0} \in \mathbb{N}$ such that $\left\|w_{n}-q\right\|<\delta$ for each $n \geq n_{0}$. As in the proof of [24, Theorem 8], we consider the following two cases:

(i) There exists $n_{1} \geq n_{0}$ such that $\left\|x_{n_{1}}-q\right\|<\epsilon+\delta$.

(ii) $\left\|x_{n}-q\right\| \geq \epsilon+\delta$ for every $n \geq n_{0}$.

In case (i), it holds that

$$
\left\|x_{n_{1}+1}-w_{n_{1}+1}\right\| \leq\left\|f\left(x_{n_{1}}\right)-f(q)\right\|<\epsilon .
$$

Thus we get

$$
\left\|x_{n_{1}+1}-q\right\| \leq\left\|x_{n_{1}+1}-w_{n_{1}+1}\right\|+\left\|w_{n_{1}+1}-q\right\|<\epsilon+\delta,
$$

which means that

$$
\limsup _{n \rightarrow \infty}\left\|x_{n}-q\right\| \leq \epsilon+\delta<\limsup _{n \rightarrow \infty}\left\|x_{n}-q\right\| .
$$

This is a contradiction. In case (ii), we have

$$
\left\|f\left(x_{n}\right)-f(q)\right\|<r\left\|x_{n}-q\right\|, \quad n \geq n_{0} .
$$

Thus we get

$$
\begin{aligned}
\left\|x_{n_{1}+1}-w_{n_{1}+1}\right\| & \leq\left\|f\left(x_{n}\right)-f(q)\right\| \\
& <r\left\|x_{n}-q\right\| \leq r\left(\left\|x_{n}-w_{n}\right\|+\left\|w_{n}-q\right\|\right),
\end{aligned}
$$


It follows from (44) that

$$
\begin{aligned}
\limsup _{n \rightarrow \infty}\left\|x_{n}-w_{n}\right\| & =\limsup _{n \rightarrow \infty}\left\|x_{n_{1}+1}-w_{n_{1}+1}\right\| \\
& \leq r \limsup _{n \rightarrow \infty}\left\|x_{n}-w_{n}\right\| \\
& <\limsup _{n \rightarrow \infty}\left\|x_{n}-w_{n}\right\| .
\end{aligned}
$$

This is a contradiction again. Therefore, we obtain that $\lim _{n \rightarrow \infty} x_{n}=q$. Moreover, since $x_{n+1}=P_{C_{n+1}} f\left(x_{n}\right)$, we have $\left\langle f\left(x_{n}\right)-x_{n+1}, x_{n+1}-y\right\rangle \geq 0$ for each $y \in C_{n+1}$. By $\Omega \subset C_{n+1}$, we have

$$
\langle f(q)-q, q-y\rangle \geq 0, \quad \forall y \in \Omega,
$$

which is equivalent to $q=P_{\Omega} f(q)$ from the property of metric projection.

Step 5. Now, we prove that $\lim _{n \rightarrow \infty}\left\|x_{n}-u_{n}\right\|=0$. From $x_{n} \rightarrow q$ as $n \rightarrow \infty$, we have

$$
\lim _{n \rightarrow \infty}\left\|x_{n+1}-x_{n}\right\|=0 \text {. }
$$

Since $x_{n+1}=P_{C_{n+1}} f\left(x_{n}\right) \in C_{n+1}$, we have

$$
\left\|y_{n}-x_{n+1}\right\|^{2} \leq\left\|x_{n}-x_{n+1}\right\|^{2}+\theta_{n} \text {. }
$$

It follows from (55) and Lemma 2 that

$$
\begin{aligned}
\left\|y_{n}-x_{n}\right\|^{2}= & \left\|y_{n}-x_{n+1}+x_{n+1}-x_{n}\right\|^{2} \\
= & \left\|y_{n}-x_{n+1}\right\|^{2}+2\left\langle y_{n}-x_{n+1}, x_{n+1}-x_{n}\right\rangle \\
& +\left\|x_{n+1}-x_{n}\right\|^{2} \\
\leq & 2\left\|x_{n}-x_{n+1}\right\|^{2}+2\left\|y_{n}-x_{n+1}\right\| \\
& \times\left\|x_{n+1}-x_{n}\right\|+\theta_{n} .
\end{aligned}
$$

Since $\theta_{n}=\left(k_{h(n)}-1\right) \rho_{n}^{2}+e_{h(n)} \rightarrow 0$ as $n \rightarrow \infty$ and (54), we obtain

$$
\lim _{n \rightarrow \infty}\left\|x_{n}-y_{n}\right\|=0
$$

For each $p \in \Omega, m=1,2, \ldots, M$, it follows from (33) and (40) that

$$
\begin{aligned}
&\left\|\Theta_{n}^{m} x_{n}-p\right\|^{2} \\
&=\left\|F_{r_{m, n}}\left(I-r_{m, n} A_{m}\right) \Theta_{n}^{m-1} x_{n}-F_{r_{m, n}}\left(I-r_{m, n} A_{m}\right) p\right\|^{2} \\
& \leq\left\|\left(I-r_{m, n} A_{m}\right) \Theta_{n}^{m-1} x_{n}-\left(I-r_{m, n} A_{m}\right) p\right\|^{2} \\
& \leq\left\|\Theta_{n}^{m-1} x_{n}-p\right\|^{2}-r_{m, n}\left(2 \alpha_{m}-r_{m, n}\right) \\
& \times\left\|A_{m} \Theta_{n}^{m-1} x_{n}-A_{m} p\right\|^{2} \\
& \leq\left\|x_{n}-p\right\|^{2}-r_{m, n}\left(2 \alpha_{m}-r_{m, n}\right) \\
& \times\left\|A_{m} \Theta_{n}^{m-1} x_{n}-A_{m} p\right\|^{2} .
\end{aligned}
$$

By (40), (42), and (58), we have

$$
\begin{aligned}
\left\|y_{n}-p\right\|^{2} \leq & \left\|u_{n}-p\right\|^{2}+\theta_{n} \\
= & \left\|\Theta_{n}^{M} x_{n}-\Theta_{n}^{M} p\right\|+\theta_{n} \\
\leq & \left\|\Theta_{n}^{m} x_{n}-\Theta_{n}^{m} p\right\|+\theta_{n} \\
\leq & \left\|x_{n}-p\right\|^{2}-r_{m, n}\left(2 \alpha_{m}-r_{m, n}\right) \\
& \times\left\|A_{m} \Theta_{n}^{m-1} x_{n}-A_{m} p\right\|^{2}+\theta_{n},
\end{aligned}
$$

which implies that

$$
\begin{aligned}
r_{m, n}( & \left.2 \alpha_{m}-r_{m, n}\right)\left\|A_{m} \Theta_{n}^{m-1} x_{n}-A_{m} p\right\|^{2} \\
& \leq\left\|x_{n}-p\right\|^{2}-\left\|y_{n}-p\right\|^{2}+\theta_{n} \\
& \leq\left\|x_{n}-y_{n}\right\|\left(\left\|x_{n}-p\right\|+\left\|y_{n}-p\right\|\right)+\theta_{n} .
\end{aligned}
$$

Since $r_{m, n} \in[c, d] \subset\left(0,2 \alpha_{m}\right)$ for each $m=1,2, \ldots, M$ and $\theta_{n} \rightarrow 0$ as $n \rightarrow \infty$. From (57), we have

$$
\lim _{n \rightarrow \infty}\left\|A_{m} \Theta_{n}^{m-1} x_{n}-A_{m} p\right\|=0, \quad m=1,2, \ldots, M
$$

On the other hand, it follows from the nonexpansive $I$ $r_{m, n} A_{m}$ and Lemma 1 that

$$
\begin{aligned}
& \left\|\Theta_{n}^{m} x_{n}-p\right\|^{2} \\
& =\left\|F_{r_{m, n}}\left(I-r_{m, n} A_{m}\right) \Theta_{n}^{m-1} x_{n}-F_{r_{m, n}}\left(I-r_{m, n} A_{m}\right) \Theta_{n}^{m-1} p\right\|^{2} \\
& \leq\left\langle\left(I-r_{m, n} A_{m}\right) \Theta_{n}^{m-1} x_{n}-\left(I-r_{m, n} A_{m}\right) p, \Theta_{n}^{m} x_{n}-p\right\rangle \\
& =\frac{1}{2}\left[\left\|\left(I-r_{m, n} A_{m}\right) \Theta_{n}^{m-1} x_{n}-\left(I-r_{m, n} A_{m}\right) p\right\|^{2}\right. \\
& \quad+\left\|\Theta_{n}^{m} x_{n}-p\right\|^{2} \\
& \left.\quad-\left\|\left(I-r_{m, n} A_{m}\right) \Theta_{n}^{m-1} x_{n}-\left(I-r_{m, n} A_{m}\right) p-\left(\Theta_{n}^{m} x_{n}-p\right)\right\|^{2}\right] \\
& \leq \frac{1}{2}\left[\left\|\Theta_{n}^{m-1} x_{n}-p\right\|^{2}+\left\|\Theta_{n}^{m} x_{n}-p\right\|^{2}\right. \\
& \left.\quad-\left\|\Theta_{n}^{m-1} x_{n}-\Theta_{n}^{m} x_{n}-r_{m, n}\left(A_{m} \Theta_{n}^{m-1} x_{n}-A_{m} p\right)\right\|^{2}\right],
\end{aligned}
$$


which implies that

$$
\begin{aligned}
\left\|\Theta_{n}^{m} x_{n}-p\right\|^{2} & \\
\leq & \left\|\Theta_{n}^{m-1} x_{n}-p\right\|^{2} \\
& -\left\|\Theta_{n}^{m-1} x_{n}-\Theta_{n}^{m} x_{n}-r_{m, n}\left(A_{m} \Theta_{n}^{m-1} x_{n}-A_{m} p\right)\right\|^{2} \\
= & \left\|\Theta_{n}^{m-1} x_{n}-p\right\|^{2}-\left\|\Theta_{n}^{m-1} x_{n}-\Theta_{n}^{m} x_{n}\right\|^{2} \\
& -r_{m, n}^{2}\left\|A_{m} \Theta_{n}^{m-1} x_{n}-A_{m} p\right\|^{2} \\
& +2 r_{m, n}\left\langle\Theta_{n}^{m-1} x_{n}-\Theta_{n}^{m} x_{n}, A_{m} \Theta_{n}^{m-1} x_{n}-A_{m} p\right\rangle \\
\leq & \left\|x_{n}-p\right\|^{2}-\left\|\Theta_{n}^{m-1} x_{n}-\Theta_{n}^{m} x_{n}\right\|^{2} \\
& +2 r_{m, n}\left\|\Theta_{n}^{m-1} x_{n}-\Theta_{n}^{m} x_{n}\right\| \\
& \cdot\left\|A_{m} \Theta_{n}^{m-1} x_{n}-A_{m} p\right\| .
\end{aligned}
$$

From (40), (42), and (63), we obtain

$$
\begin{aligned}
\left\|y_{n}-p\right\|^{2} \leq & \left\|u_{n}-p\right\|^{2}+\theta_{n} \\
= & \left\|\Theta_{n}^{M} x_{n}-p\right\|+\theta_{n} \\
\leq & \left\|\Theta_{n}^{m} x_{n}-p\right\|+\theta_{n} \\
\leq & \left\|x_{n}-p\right\|^{2}-\left\|\Theta_{n}^{m-1} x_{n}-\Theta_{n}^{m} x_{n}\right\|^{2} \\
& +2 r_{m, n}\left\|\Theta_{n}^{m-1} x_{n}-\Theta_{n}^{m} x_{n}\right\| \\
& \cdot\left\|A_{m} \Theta_{n}^{m-1} x_{n}-A_{m} p\right\|+\theta_{n},
\end{aligned}
$$

which implies that

$$
\begin{aligned}
& \left\|\Theta_{n}^{m-1} x_{n}-\Theta_{n}^{m} x_{n}\right\|^{2} \\
& \leq\left\|x_{n}-p\right\|^{2}-\left\|y_{n}-p\right\|^{2}+2 r_{m, n}\left\|\Theta_{n}^{m-1} x_{n}-\Theta_{n}^{m} x_{n}\right\| \\
& \quad \times\left\|A_{m} \Theta_{n}^{m-1} x_{n}-A_{m} p\right\|+\theta_{n} \\
& \leq\left\|x_{n}-y_{n}\right\|\left(\left\|x_{n}-p\right\|+\left\|y_{n}-p\right\|\right) \\
& \quad+2 r_{m, n}\left\|\Theta_{n}^{m-1} x_{n}-\Theta_{n}^{m} x_{n}\right\|\left\|A_{m} \Theta_{n}^{m-1} x_{n}-A_{m} p\right\|+\theta_{n} .
\end{aligned}
$$

It follows from (57) and (65) that

$$
\lim _{n \rightarrow \infty}\left\|\Theta_{n}^{m-1} x_{n}-\Theta_{n}^{m} x_{n}\right\|=0, \quad m=1,2, \ldots, M .
$$

Note that

$$
\begin{aligned}
\left\|x_{n}-u_{n}\right\| \leq & \left\|\Theta_{n}^{0} x_{n}-\Theta_{n}^{1} x_{n}\right\| \\
& +\left\|\Theta_{n}^{1} x_{n}-\Theta_{n}^{2} x_{n}\right\|+\cdots+\left\|\Theta_{n}^{M-1} x_{n}-\Theta_{n}^{M} x_{n}\right\| .
\end{aligned}
$$

Therefore,

$$
\lim _{n \rightarrow \infty}\left\|x_{n}-u_{n}\right\|=0
$$

Step 6. Finally, we prove that $q \in\left(\bigcap_{i=1}^{N} \operatorname{Fix}\left(T_{i}\right)\right) \cap\left(\bigcap_{m=1}^{M} \mathrm{EP}\right.$ $\left.\left(F_{m}, A_{m}\right)\right)$. To do this, we first show that $q \in \bigcap_{i=1}^{N} \operatorname{Fix}\left(T_{i}\right)$. Note that

$$
\begin{aligned}
\left\|u_{n+1}-u_{n}\right\| \leq & \left\|u_{n+1}-x_{n+1}\right\| \\
& +\left\|x_{n+1}-x_{n}\right\|+\left\|x_{n}-u_{n}\right\| .
\end{aligned}
$$

From (54) and (68), we get

$$
\lim _{n \rightarrow \infty}\left\|u_{n+1}-u_{n}\right\|=0 .
$$

It follows that

$$
\lim _{n \rightarrow \infty}\left\|u_{n+i}-u_{n}\right\|=0, \quad i=1,2, \ldots, N .
$$

For any positive integer $n \geq N$, note that $n=[h(n)-1] N+i(n)$, where $i=i(n)=1,2, \ldots, N$. By (19) and the conditions $0<$ $a \leq \alpha_{n} \leq 1$ and $0<b \leq \beta_{n} \leq 1-\lambda$, we have

$$
\begin{aligned}
\left\|u_{n}-T_{i(n)}^{h(n)} u_{n}\right\| & =\frac{1}{\beta_{n}}\left\|z_{n}-u_{n}\right\| \\
& =\frac{1}{\alpha_{n} \beta_{n}}\left\|y_{n}-u_{n}\right\| \\
& \leq \frac{1}{a b}\left(\left\|y_{n}-x_{n}\right\|+\left\|x_{n}-u_{n}\right\|\right) .
\end{aligned}
$$

From (57) and (68), we get

$$
\lim _{n \rightarrow \infty}\left\|u_{n}-T_{i(n)}^{h(n)} u_{n}\right\|=0 .
$$

By the fact that $h(n)=h(n-N)+1$ and $i(n)=i(n-N)$, we observe that

$$
\begin{aligned}
\left\|u_{n}-T_{i(n)}^{h(n)-1} u_{n}\right\| \leq & \left\|u_{n}-u_{n-N}\right\| \\
& +\left\|u_{n-N}-T_{i(n-N)}^{h(n-N)} u_{n-N}\right\| \\
& +\left\|T_{i(n-N)}^{h(n-N)} u_{n-N}-T_{i(n)}^{h(n)-1} u_{n}\right\| .
\end{aligned}
$$

Applying (71), (73), and Lemma 6, we obtain

$$
\lim _{n \rightarrow \infty}\left\|u_{n}-T_{i(n)}^{h(n)-1} u_{n}\right\|=0 .
$$

By the uniformly $L$-Lipschitzian of $T_{i}$, we have

$$
\begin{aligned}
\left\|u_{n}-T_{n} u_{n}\right\| & \leq\left\|u_{n}-T_{i(n)}^{h(n)} u_{n}\right\|+\left\|T_{i(n)}^{h(n)} u_{n}-T_{i(n)} u_{n}\right\| \\
& \leq\left\|u_{n}-T_{i(n)}^{h(n)} u_{n}\right\|+L\left\|u_{n}-T_{i(n)}^{h(n)-1} u_{n}\right\| .
\end{aligned}
$$

It follows from (73) and (75) that

$$
\lim _{n \rightarrow \infty}\left\|u_{n}-T_{n} u_{n}\right\|=0
$$


Since

$$
\begin{aligned}
\left\|u_{n}-T_{n+i} u_{n}\right\| & \leq\left\|u_{n}-u_{n+i}\right\|+\left\|u_{n+i}-T_{n+i} u_{n+i}\right\| \\
& +\left\|T_{n+i} u_{n+i}-T_{n+i} u_{n}\right\| \\
& \leq(1+L)\left\|u_{n}-u_{n+i}\right\|+\left\|u_{n+i}-T_{n+i} u_{n+i}\right\| .
\end{aligned}
$$

Combining (71) and (77), we obtain

$$
\lim _{n \rightarrow \infty}\left\|u_{n}-T_{i} u_{n}\right\|=0, \quad i=1,2, \ldots, N .
$$

Moreover, for each $i=1,2, \ldots, N$, we have

$$
\left\|x_{n}-T_{i} x_{n}\right\| \leq\left\|x_{n}-u_{n}\right\|+\left\|u_{n}-T_{i} u_{n}\right\|+\left\|T_{i} u_{n}-T_{i} x_{n}\right\| .
$$

This implies that

$$
\lim _{n \rightarrow \infty}\left\|x_{n}-T_{i} x_{n}\right\|=0, \quad i=1,2, \ldots, N .
$$

Note that $x_{n} \rightarrow q$ as $n \rightarrow \infty$. It follows from (81) and Lemma 5 that $q \in \bigcap_{i=1}^{N} \operatorname{Fix}\left(T_{i}\right)$.

Next, we show that $q \in \bigcap_{m=1}^{M} \operatorname{EP}\left(F_{m}, A_{m}\right)$. From Lemma 1 and since $\Theta_{n}^{m} x_{n}=F_{r_{m, n}}\left(I-r_{m, n} A_{m}\right) \Theta_{n}^{m-1} x_{n}, m=1,2, \ldots, M$, we have

$$
\begin{aligned}
& F_{m}\left(\Theta_{n}^{m} x_{n}, y\right)+\left\langle A_{m} \Theta_{n}^{m-1} x_{n}, y-\Theta_{n}^{m} x_{n}\right\rangle \\
& \quad+\frac{1}{r_{m, n}}\left\langle y-\Theta_{n}^{m} x_{n}, \Theta_{n}^{m} x_{n}-\Theta_{n}^{m-1} x_{n}\right\rangle \geq 0,
\end{aligned}
$$

$\forall y \in C$.

By (A2), we have

$$
\begin{aligned}
& \left\langle A_{m} \Theta_{n}^{m-1} x_{n}, y-\Theta_{n}^{m} x_{n}\right\rangle \\
& \quad+\frac{1}{r_{m, n}}\left\langle y-\Theta_{n}^{m} x_{n}, \Theta_{n}^{m} x_{n}-\Theta_{n}^{m-1} x_{n}\right\rangle \\
& \geq F_{m}\left(y, \Theta_{n}^{m} x_{n}\right), \quad \forall y \in C .
\end{aligned}
$$

Let $z_{t}=t y+(1-t) q$ for all $t \in(0,1]$ and $y \in C$. This implies that $z_{t} \in C$. Then, we have

$$
\begin{aligned}
\left\langle A_{m} z_{t}, z_{t}-\Theta_{n}^{m} x_{n}\right\rangle & \\
\geq & \left\langle A_{m} z_{t}, z_{t}-\Theta_{n}^{m} x_{n}\right\rangle-\left\langle A_{m} \Theta_{n}^{m-1} x_{n}, z_{t}-\Theta_{n}^{m} x_{n}\right\rangle \\
& -\left\langle z_{t}-\Theta_{n}^{m} x_{n}, \frac{\Theta_{n}^{m} x_{n}-\Theta_{n}^{m-1} x_{n}}{r_{m, n}}\right\rangle+F_{m}\left(z_{t}, \Theta_{n}^{m} x_{n}\right) \\
\geq & \left\langle A_{m} z_{t}-A_{m} \Theta_{n}^{m} x_{n}, z_{t}-\Theta_{n}^{m} x_{n}\right\rangle \\
& +\left\langle A_{m} \Theta_{n}^{m} x_{n}-A_{m} \Theta_{n}^{m-1} x_{n}, z_{t}-\Theta_{n}^{m} x_{n}\right\rangle \\
& -\left\langle z_{t}-\Theta_{n}^{m} x_{n}, \frac{\Theta_{n}^{m} x_{n}-\Theta_{n}^{m-1} x_{n}}{r_{m, n}}\right\rangle+F_{m}\left(z_{t}, \Theta_{n}^{m} x_{n}\right) .
\end{aligned}
$$

From (66), we have $\left\|A_{m} \Theta_{n}^{m} x_{n}-A_{m} \Theta_{n}^{m-1} x_{n}\right\| \rightarrow 0$ as $n \rightarrow$ $\infty$. Moreover, by (A4) and the monotonicity of $A_{m}$, we obtain

$$
\left\langle A_{m} z_{t}, z_{t}-q\right\rangle \geq F_{m}\left(z_{t}, q\right), \quad m=1,2, \ldots, M .
$$

Using (A1), (A4), and (85), we obtain

$$
\begin{aligned}
0 & =F_{m}\left(z_{t}, z_{t}\right) \leq t F_{m}\left(z_{t}, y\right)+(1-t) F_{m}\left(z_{t}, q\right) \\
& \leq t F_{m}\left(z_{t}, y\right)+(1-t)\left\langle A_{m} z_{t}, z_{t}-q\right\rangle \\
& \leq t F_{m}\left(z_{t}, y\right)+(1-t) t\left\langle A_{m} z_{t}, y-q\right\rangle .
\end{aligned}
$$

and hence

$$
F_{m}\left(z_{t}, y\right)+(1-t)\left\langle A_{m} z_{t}, y-q\right\rangle \geq 0 \text {. }
$$

Let $t \rightarrow 0$, from (A3) and (87), we have

$$
F_{m}(q, y)+\left\langle A_{m} q, y-q\right\rangle \geq 0, \quad \forall y \in C, \quad m=1,2, \ldots, M .
$$

This implies that $q \in \mathrm{EP}\left(F_{m}, A_{m}\right), m=1,2, \ldots, M$. Therefore, $q \in \bigcap_{m=1}^{M} \operatorname{EP}\left(F_{m}, A_{m}\right)$. Consequently, we obtain that $q \in \Omega$. This completes the proof.

We also obtain the following results by using the viscosityhybrid projection methods, which extend and improve the hybrid method (CQ) proposed by Sahu et al. [11] and Hu and Cai [12].

Theorem 11. Let $C$ be a nonempty closed convex subset of Hilbert space $H$. Let $F_{m}: C \times C \rightarrow \mathbb{R}$ be a bifunction satisfying (A1)-(A4), and let $A_{m}: C \rightarrow H$ be an $\alpha_{m^{-}}$ inverse strongly monotone mapping, for each $m=1,2, \ldots, M$. Let $T_{i}: C \rightarrow C$ be a uniformly $L_{i}$-Lipschitz continuous and asymptotically $\lambda_{i}$-strict pseudocontractive mapping in the intermediate sense with the sequences $\left\{k_{n, i}\right\}$ and $\left\{e_{n, i}\right\}$ for each $i=1,2, \ldots, N$. If $f$ is a Meir-Keeler contraction of $C$ into itself and $\Omega=\left(\bigcap_{i=1}^{N} \operatorname{Fix}\left(T_{i}\right)\right) \cap\left(\bigcap_{m=1}^{M} \operatorname{EP}\left(F_{m}, A_{m}\right)\right)$ is nonempty and bounded. Let $\left\{x_{n}\right\}$ be a sequence defined by

$$
\begin{gathered}
x_{1} \in C, \quad Q_{1}=C, \\
u_{n}=F_{r_{M, n}}^{A_{M}} F_{r_{M-1, n}}^{A_{M-1}} \cdots F_{r_{2, n}}^{A_{2}} F_{r_{1, n}}^{A_{1}} x_{n}, \\
z_{n}=\left(1-\beta_{n}\right) u_{n}+\beta_{n} T_{i(n)}^{h(n)} u_{n}, \\
y_{n}=\left(1-\alpha_{n}\right) u_{n}+\alpha_{n} z_{n}, \\
C_{n}=\left\{w \in C:\left\|y_{n}-w\right\|^{2} \leq\left\|x_{n}-w\right\|^{2}+\theta_{n}\right\}, \\
Q_{n}=\left\{u \in Q_{n-1}:\left\langle f\left(x_{n-1}\right)-x_{n}, x_{n}-u\right\rangle \geq 0\right\}, \\
x_{n+1}=P_{C_{n} \cap Q_{n}} f\left(x_{n}\right),
\end{gathered}
$$

where $\theta_{n}=\left(k_{h(n)}-1\right) \rho_{n}^{2}+e_{h(n)} \rightarrow 0$ as $n \rightarrow \infty$ and $\rho_{n}=$ $\sup \left\{\left\|x_{n}-p\right\|: p \in \Omega\right\}<\infty$. Assume that $\left\{\alpha_{n}\right\}$ and $\left\{\beta_{n}\right\}$ are sequences in $[0,1]$ such that $0<a \leq \alpha_{n} \leq 1,0<b \leq \beta_{n} \leq 1-\lambda$ and $\left\{r_{m, n}\right\} \subset(0, \infty)$ such that $r_{m, n} \in[c, d] \subset\left(0,2 \alpha_{m}\right)$, for each $m=1,2, \ldots, M$. Then the sequence $\left\{x_{n}\right\}$ generated by (89) converges strongly to $q=P_{\Omega} f(q)$. 
Proof. We have that $C_{n}$ and $Q_{n}$ are closed convex subsets of $H$ and $\Omega \subset C_{n}$ for every $n \in \mathbb{N}$. We only prove that $\Omega \subset Q_{n}$ for every $n \in \mathbb{N}$ and that a sequence $\left\{x_{n}\right\}$ is well-defined. We have $x_{1} \in C$ and $\Omega \subset Q_{1}=C$. Assume that $x_{k} \in C$ and $\Omega \subset Q_{k}$ for some $k \in \mathbb{N}$. Since $\Omega \subset C_{k} \cap Q_{k}$, there exists a unique element $x_{k+1}=P_{C_{k} \cap Q_{k}} f\left(x_{k}\right)$, and hence

$$
\left\langle f\left(x_{k}\right)-x_{k+1}, x_{k+1}-y\right\rangle \geq 0, \quad \forall y \in C_{k} \cap Q_{k} .
$$

This implies that

$$
\left\langle f\left(x_{k}\right)-x_{k+1}, x_{k+1}-y\right\rangle \geq 0, \quad \forall y \in \Omega .
$$

That is, $\Omega \subset Q_{k+1}$. Therefore, we prove that $\Omega \subset Q_{n}$.

On the other hand, $P_{\bigcap_{n=1}^{\infty} Q_{n}} f$ is a Meir-Keeler contraction on $C$, there exists a unique element $q=P_{\bigcap_{n=1}^{\infty} Q_{n}} f(q) \in$ $\bigcap_{n=1}^{\infty} Q_{n}$ by Lemma 7. Let $z_{n}=P_{Q_{n}} f(q)$ for each $n \in \mathbb{N}$. Since $\Omega \subset Q_{n+1} \subset Q_{n}$, it follows from Lemma 9 that $z_{n} \rightarrow$ $q=P_{\bigcap_{n=1}^{\infty} Q_{n}} f(q)$. We also have $x_{n}=P_{Q_{n}} f\left(x_{n-1}\right)$ by the definition of $Q_{n}$. Therefore, as in the proof of Theorem 10, we get $x_{n} \rightarrow q$, and the desired conclusion follows immediately from Theorem 10. This completes the proof.

If $M=N=1$, we obtain the following corollary for a general equilibrium problem and asymptotically strict pseudocontraction in the intermediate sense as a special cases.

Theorem 12. Let $C$ be a nonempty closed convex subset of Hilbert space $H$. Let $F: C \times C \rightarrow \mathbb{R}$ be a bifunction satisfying (A1)-(A4) and $A: C \rightarrow H$ be an $\alpha$-inverse strongly monotone mapping. Let $T: C \rightarrow C$ be a uniformly L-Lipschitz continuous and asymptotically $\lambda$-strict pseudocontractive mapping in the intermediate sense with the sequences $\left\{k_{n}\right\}$ and $\left\{e_{n}\right\}$. If $f$ is a Meir-Keeler contraction of $C$ into itself and $\Omega=\operatorname{Fix}(T) \cap$ $\operatorname{EP}(F, A)$ is nonempty and bounded. Let $\left\{x_{n}\right\}$ be a sequence defined by

$$
\begin{gathered}
x_{1} \in C, \quad C_{1}=C, \\
F\left(u_{n}, y\right)+\left\langle A x_{n}, y-u_{n}\right\rangle \\
+\frac{1}{r_{n}}\left\langle y-u_{n}, u_{n}-x_{n}\right\rangle \geq 0, \quad \forall y \in C, \\
z_{n}=\left(1-\beta_{n}\right) u_{n}+\beta_{n} T^{n} u_{n}, \\
y_{n}=\left(1-\alpha_{n}\right) u_{n}+\alpha_{n} z_{n}, \\
C_{n+1}=\left\{w \in C_{n}:\left\|y_{n}-w\right\|^{2} \leq\left\|x_{n}-w\right\|^{2}+\theta_{n}\right\}, \\
x_{n+1}=P_{C_{n+1}} f\left(x_{n}\right),
\end{gathered}
$$

where $\theta_{n}=\left(k_{n}-1\right) \rho_{n}^{2}+e_{n} \rightarrow 0$ as $n \rightarrow \infty$ and $\rho_{n}=\sup \left\{\| x_{n}-\right.$ $p \|: p \in \Omega\}<\infty$. Assume that $\left\{\alpha_{n}\right\}$ and $\left\{\beta_{n}\right\}$ are sequences in $[0,1]$ such that $0<a \leq \alpha_{n} \leq 1,0<b \leq \beta_{n} \leq 1-\lambda$ and $\left\{r_{n}\right\} \subset(0, \infty)$ such that $r_{n} \in[c, d] \subset(0,2 \alpha)$. Then the sequence $\left\{x_{n}\right\}$ generated by (92) converges strongly to $q=P_{\Omega} f(q)$.

If $M=N=1$ and $F=0$, the general equilibrium problem (1) reduces into the classical variational inequality problem (3), we obtain the following corollary as a special case of Theorems 10 and 12 .
Theorem 13. Let $C$ be a nonempty closed convex subset of Hilbert space $H$. Let $A: C \rightarrow H$ be an $\alpha$-inverse strongly monotone mapping. Let $T: C \rightarrow C$ be a uniformly L-Lipschitz continuous and asymptotically $\lambda$-strict pseudocontractive mapping in the intermediate sense with the sequences $\left\{k_{n}\right\}$ and $\left\{e_{n}\right\}$. If $f$ is a Meir-Keeler contraction of $C$ into itself and $\Omega=$ $\operatorname{Fix}(T) \cap \operatorname{VI}(C, A)$ is nonempty and bounded. Let $\left\{x_{n}\right\}$ be a sequence defined by

$$
\begin{gathered}
x_{1} \in C, \quad C_{1}=C, \\
y_{n}=\left(1-\alpha_{n}\right) x_{n}+\alpha_{n} T^{n} P_{C}\left(x_{n}-r_{n} A x_{n}\right), \\
C_{n+1}=\left\{w \in C_{n}:\left\|y_{n}-w\right\|^{2} \leq\left\|x_{n}-w\right\|^{2}+\theta_{n}\right\}, \\
x_{n+1}=P_{C_{n+1}} f\left(x_{n}\right),
\end{gathered}
$$

where $\theta_{n}=\left(k_{n}-1\right) \rho_{n}^{2}+e_{n} \rightarrow 0$ as $n \rightarrow \infty$ and $\rho_{n}=$ $\sup \left\{\left\|x_{n}-p\right\|: p \in \Omega\right\}<\infty$. Assume that $\left\{\alpha_{n}\right\}$ is a sequence in $[0,1]$ such that $0<b \leq \alpha_{n} \leq 1-\lambda$ and $\left\{r_{n}\right\} \subset(0, \infty)$ such that $r_{n} \in[c, d] \subset(0,2 \alpha)$. Then the sequence $\left\{x_{n}\right\}$ generated by (93) converges strongly to $q=P_{\Omega} f(q)$.

Proof. If $F=0$, the general equilibrium problem (1) reduces into the classical variational inequality problem (3), and

$$
\left\langle A x_{n}, y-u_{n}\right\rangle+\frac{1}{r_{n}}\left\langle y-u_{n}, u_{n}-x_{n}\right\rangle \geq 0, \quad \forall y \in C,
$$

which is equivalent to

$$
\left\langle y-u_{n}, u_{n}-\left(x_{n}-r_{n} A x_{n}\right)\right\rangle \geq 0, \quad \forall y \in C .
$$

Therefore, we have $u_{n}=P_{C}\left(x_{n}-r_{n} A x_{n}\right)$. The desired conclusion follows immediately from Theorem 10 (Set $\alpha_{n}=1$, $\left.\beta_{n}=\alpha_{n}\right)$. This completes the proof.

\section{Acknowledgments}

This work was supported by the National Science Foundation of China (11001287, 11271388), Natural Science Foundation Project of Chongqing (CSTC 2012jjA00039), and the Science and Technology Research Project of Chongqing Municipal Education Commission (KJ130712, KJ130731).

\section{References}

[1] E. Blum and W. Oettli, "From optimization and variational inequalities to equilibrium problems," The Mathematics Student, vol. 63, no. 1-4, pp. 123-145, 1994.

[2] P. L. Combettes and S. A. Hirstoaga, "Equilibrium programming in Hilbert spaces," Journal of Nonlinear and Convex Anslysis, vol. 6, pp. 117-136, 2005.

[3] L. C. Ceng and J. C. Yao, "A hybrid iterative scheme for mixed equilibrium problems and fixed point problems," Journal of Computational and Applied Mathematics, vol. 214, no. 1, pp. 186201, 2008.

[4] X. Qin, S. Y. Cho, and S. M. Kang, "Some results on generalized equilibrium problems involving a family of nonexpansive mappings," Applied Mathematics and Computation, vol. 217, no. 7, pp. 3113-3126, 2010. 
[5] W. A. Kirk, "Fixed point theorems for non-Lipschitzian mappings of asymptotically nonexpansive type," Israel Journal of Mathematics, vol. 17, no. 4, pp. 339-346, 1974.

[6] H. K. Xu, "Existence and convergence for fixed points of mappings of asymptotically nonexpansive type," Nonlinear Analysis, vol. 16, no. 12, pp. 1139-1146, 1991.

[7] F. E. Browder and W. V. Petryshyn, "Construction of fixed points of nonlinear mappings in Hilbert space," Journal of Mathematical Analysis and Applications, vol. 20, no. 2, pp. 197228, 1967.

[8] G. Marino and H. K. Xu, "Weak and strong convergence theorems for strict pseudo-contractions in Hilbert spaces," Journal of Mathematical Analysis and Applications, vol. 329, no. 1, pp. 336-346, 2007.

[9] L. Qihou, "Convergence theorems of the sequence of iterates for asymptotically demicontractive and hemicontractive mappings," Nonlinear Analysis: Theory, Methods and Applications, vol. 26, no. 11, pp. 1835-1842, 1996.

[10] X. L. Qin, Y. J. Cho, S. M. Kang, and M. Shang, "A hybrid iterative scheme for asymptotically $k$-strict pseudo-contractions in Hilbert spaces," Nonlinear Analysis: Theory, Methods and Applications, vol. 70, no. 5, pp. 1902-1911, 2009.

[11] D. R. Sahu, H. K. Xu, and J. C. Yao, "Asymptotically strict pseudocontractive mappings in the intermediate sense," Nonlinear Analysis: Theory, Methods and Applications, vol. 70, no. 10, pp. 3502-3511, 2009.

[12] C. S. Hu and G. Cai, "Convergence theorems for equilibrium problems and fixed point problems of a finite family of asymptotically $k$-strictly pseudocontractive mappings in the intermediate sense," Computers and Mathematics with Applications, vol. 61, no. 1, pp. 79-93, 2011.

[13] A. Moudafi, "Viscosity approximation methods for fixed-points problems," Journal of Mathematical Analysis and Applications, vol. 241, no. 1, pp. 46-55, 2000.

[14] S. Takahashi and W. Takahashi, "Viscosity approximation methods for equilibrium problems and fixed point problems in Hilbert spaces," Journal of Mathematical Analysis and Applications, vol. 331, no. 1, pp. 506-515, 2007.

[15] I. Inchan, "Viscosity iteration method for generalized equilibrium problems and fixed point problems of finite family of nonexpansive mappings," Applied Mathematics and Computation, vol. 219, no. 6, pp. 2949-2959, 2012.

[16] Y. Kimura and K. Nakajo, "Viscosity approximations by the shrinking projection method in Hilbert spaces," Computers and Mathematics with Applications, vol. 63, no. 9, pp. 1400-1408, 2012.

[17] D. J. Wen, "Strong convergence theorems for equilibrium problems and $k$-strict pseudocontractions in hilbert spaces," Abstract and Applied Analysis, vol. 2011, Article ID 276874, 13 pages, 2011.

[18] D. J. Wen and Y. A. Chen, "Strong convergence of modified general iterative method for generalized equilibrium problems and fixed point problems of $k$-strict pseudo-contractions," Fixed Point Theory and Applications, vol. 2012, article 125, 2012.

[19] H. Piri, "A general iterative method for finding common solutions of system of equilibrium problems, system of variational inequalities and fixed point problems," Mathematical and Computer Modelling, vol. 55, no. 3-4, pp. 1622-1638, 2012.

[20] Y. Shehu, "Iterative approximation for common solutions of equilibrium problems, variational inequality and fixed point problems," Mathematical and Computer Modelling, vol. 57, no. 5-6, pp. 1489-1503, 2013.
[21] W. Takahashi, Nonlinear Functional Analysis, Yokohama Publishers, Yokohama, Japan, 2000.

[22] S. Banach, "Sur les opérations dans les ensembles abstraits et leur application aux équations intégrales," Fundamenta Mathematicae, vol. 3, pp. 133-181, 1922.

[23] A. Meir and E. Keeler, "A theorem on contraction mappings," Journal of Mathematical Analysis and Applications, vol. 28, no. 2, pp. 326-329, 1969.

[24] T. Suzuki, "Moudafi's viscosity approximations with MeirKeeler contractions," Journal of Mathematical Analysis and Applications, vol. 325, no. 1, pp. 342-352, 2007.

[25] U. Mosco, "Convergence of convex sets and of solutions of variational inequalities," Advances in Mathematics, vol. 3, no. 4, pp. 510-585, 1969.

[26] G. Beer, Topologies on Closed and Closed Convex Sets, Kluwer Academic Publishers, Dordrecht, The Netherlands, 1993.

[27] M. Tsukada, "Convergence of best approximations in a smooth Banach space," Journal of Approximation Theory, vol. 40, no. 4, pp. 301-309, 1984. 


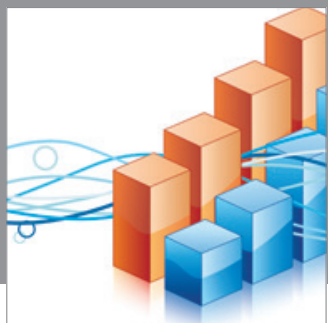

Advances in

Operations Research

mansans

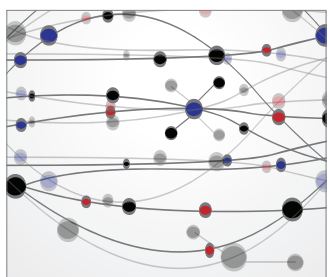

The Scientific World Journal
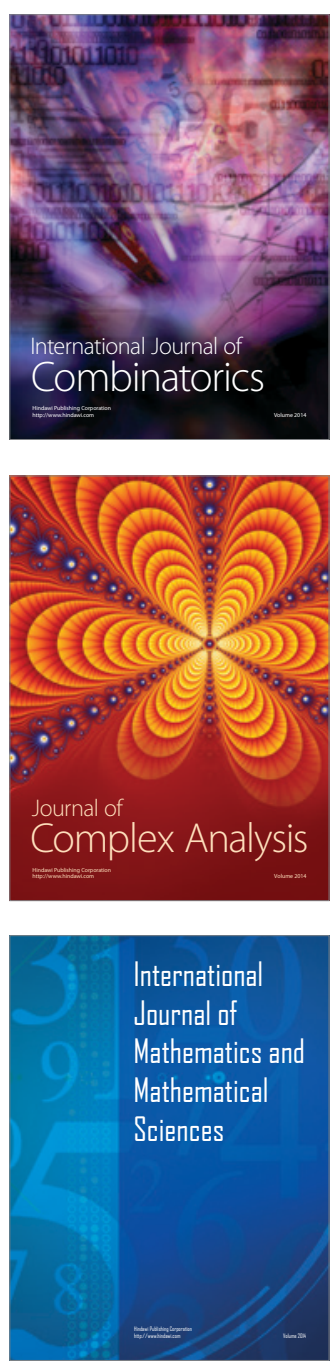
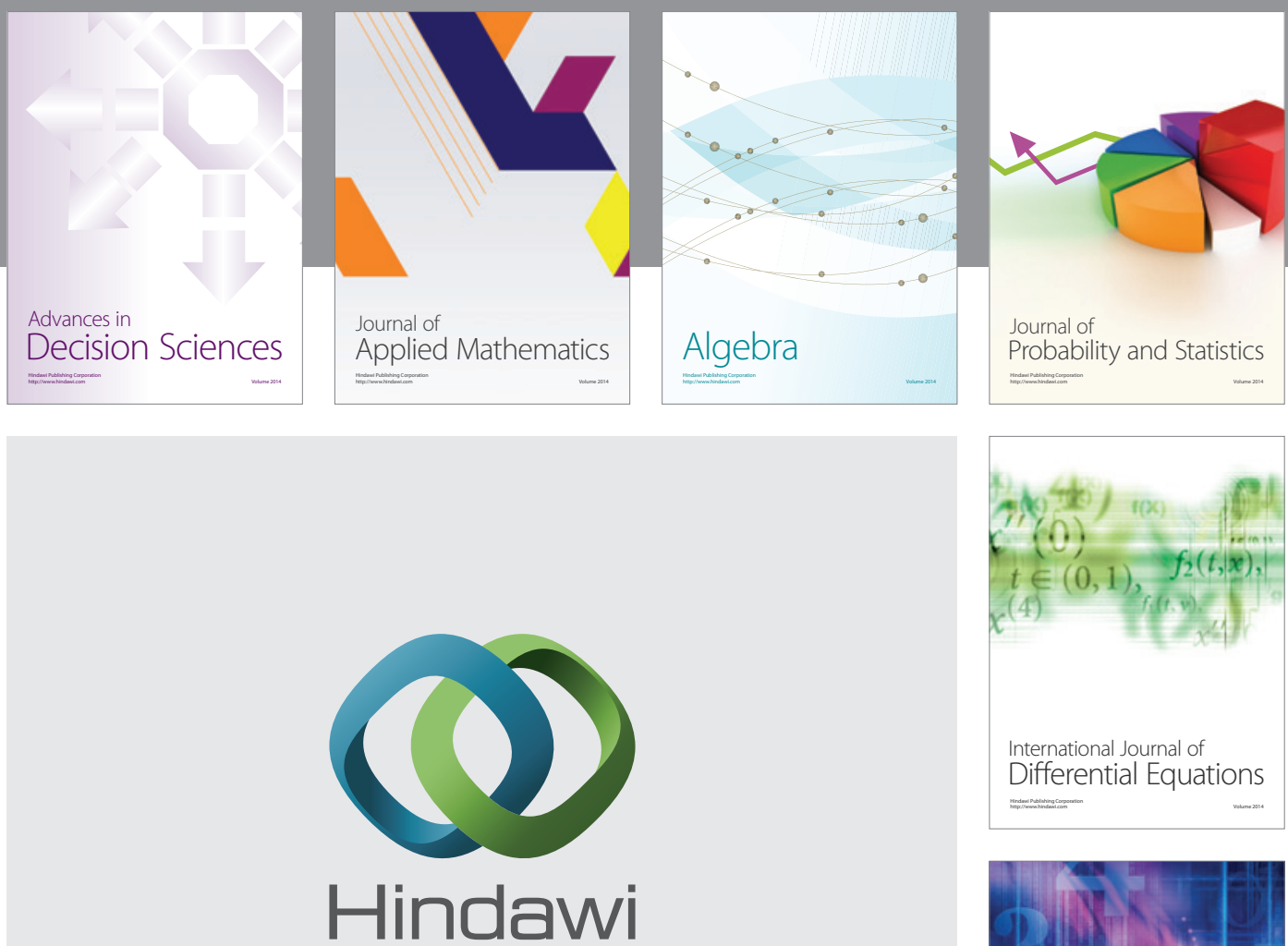

Submit your manuscripts at http://www.hindawi.com
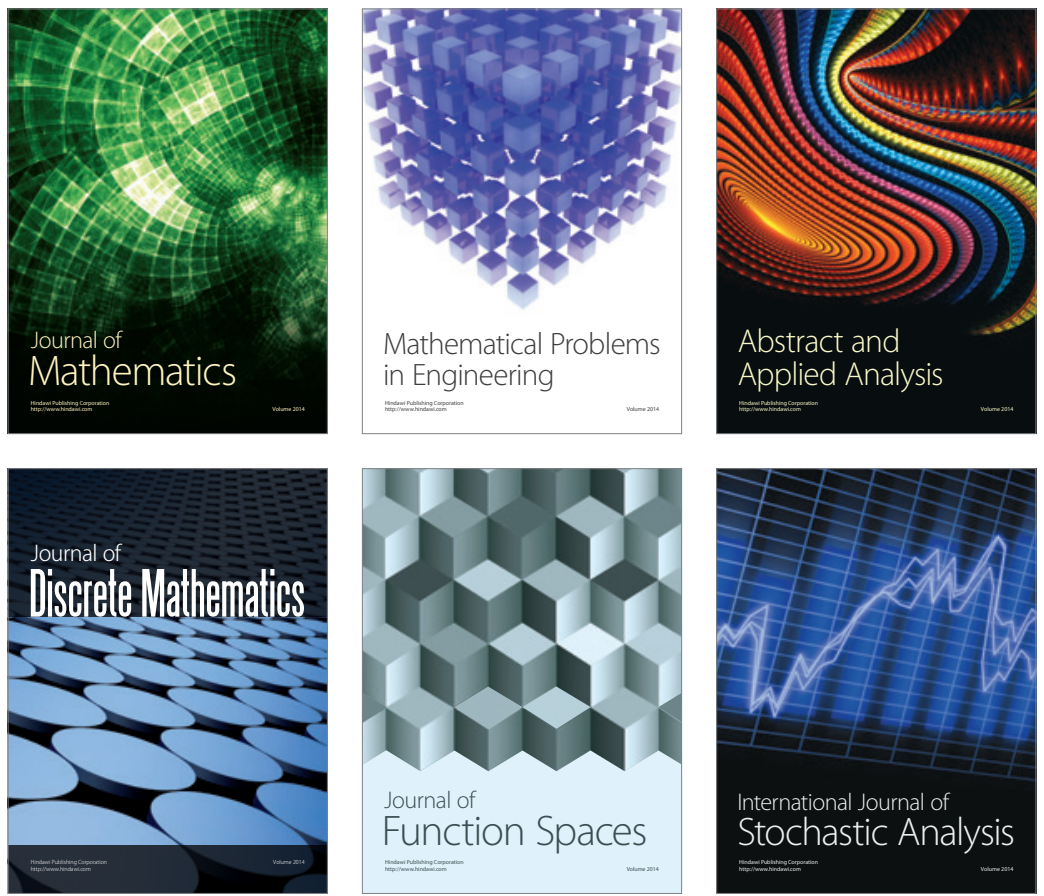

Journal of

Function Spaces

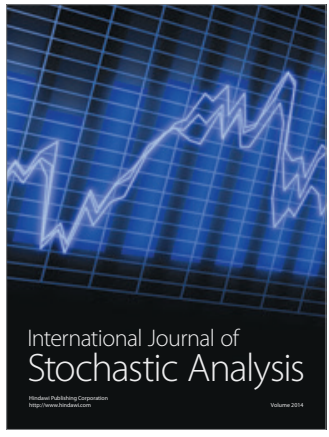

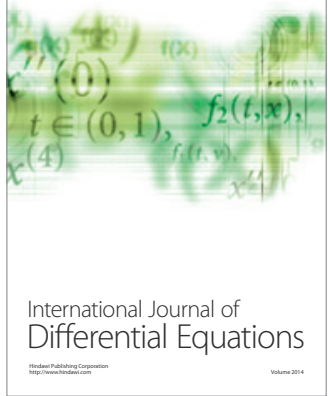
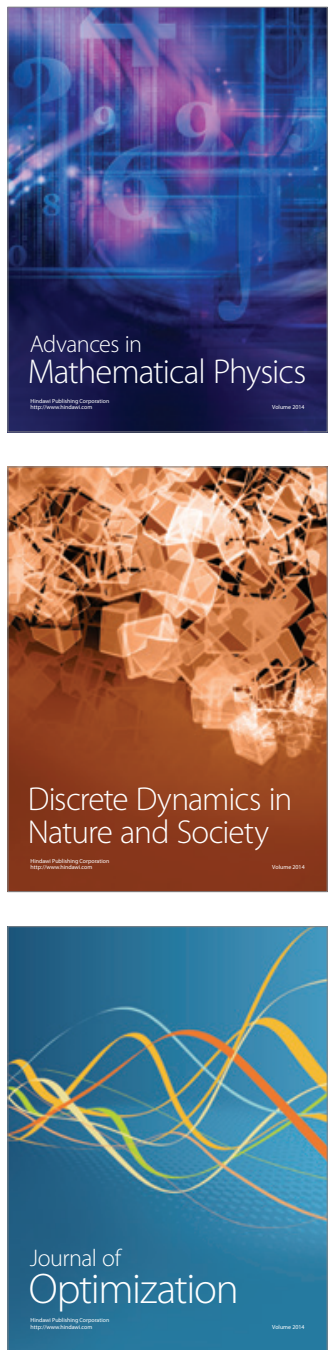